\title{
Upaya Sekuritisasi Pemerintah Bangladesh terhadap Keberadaan Pengungsi Rohingya
}

\author{
Yuliana Indra Pertiwi \\ Program Studi Ilmu Hubungan Internasional, Universitas Katolik Parahyangan, Jawa Barat - \\ Indonesia \\ Email: yulianaindrap12@gmail.com
}

\begin{abstract}
The prolong existence of Rohingya Refugees in Bangladesh had caused several problems and threatened its national security and people of Bangladesh. Bangladesh Government as securitizing actor take securitization act to protect its national security and people of Bangladesh based on policies made. This research use securitization theory or Copenhagen School to enlightened Bangladesh Government actions to securitize its national security and people of Bangladesh upon the problem caused by the existence of Rohingya refugees in Bangladesh. This research uses qualitative methods with books and journal articles related as data sources. The result of this research shows Bangladesh government actions to securitize its national security and people of Bangladesh based on its policies is the best way for both parties to repress the broadening of existing problem.
\end{abstract}

Keywords: Rohingya, Refugees, National, Security, Bangladesh, Securitization

\begin{abstract}
Abstrak
Keberadaan pengungsi Rohingya di Bangladesh dalam jangka waktu panjang telah menyebabkan timbulnya masalah-masalah yang mengancam keamanan nasional dan warga negara di Bangladesh. Pemerintah Bangladesh dalam hal ini sebagai securitisizing actor mengambil langkah sekuritisasi sebagai upaya untuk menjaga kemanana nasional dan warga negara Bangladesh berdasarkan kebijakan-kebijakan yang dibuat. Penelitian ini menggunakan pendekatan teori Sekuritisasi atau Mahzab Copenhagen School untuk menjelaskan upaya pemerintah Bangladesh untuk mesekuritisasi keamanan nasional dan warga negara Bangladesh dari masalah-masalah yang ditimbulkan terkait keberadaan pengungsi Rohingya di Bangladesh. Metode yang digunakan dalam penelitian ini adalah kualitatif dengan data yang diperoleh dari studi kepustakaan seperti buku dan artikel jurnal yang terkait. Hasil dari penelitian ini menunjukan bahwa upaya pemerintah Bangladesh dalam sekuritiasi kemanan nasional dan warga negara Bangladesh dengan kebijakan yang dibuat adalah sebagai langkah terbaik bagi kedua belah pihak untuk menekan permasalahan yang ada agar tidak semakin meluas.
\end{abstract}

Kata Kunci: Pengungsi, Rohingya, Keamanan, Nasional, Bangladesh, Sekuritisasi 


\section{PENDAHULUAN}

Sebanyak satu juta jiwa pengungsi Rohingya bernaung di Bangladesh akibat pengusiran etnis yang dilakukan oleh Myanmar (Kompas Internasional, 2018). Bangladesh menjadi salah satu negara yang bersedia menampung pengungsi Rohingya (United Nations High Commissioner for Refugees, 2109). Angka pengungsi yang begitu besar menyebabkan berbagai macam permasalahan dialami oleh Bangladesh, terutama permasalahan yang menimbulkan ancaman terhadap keamanan nasional dan warga negara Bangladesh (Rahman, 2010). Permasalahan pengungsi Rohingya bukan lagi seputar permasalahan untuk mencari suaka atau tempat untuk berlindung, tetapi permasalahan pengungsi Rohingya sudah bergeser kepada bagaimana pengungsi Rohingya yang bernaung di Bangladesh dalam jangka waktu panjang menimbulkan berbagai macam permasalahan yang mengancam kualitas hidup warga negara Bangladesh sendiri.

Permasalahan yang dialami oleh para pengungsi berubah menjadi permasalahan yang juga harus dihadapi oleh pemerintah Bangladesh dalam mengambil langkah untuk menerima jumlah pengungsi masuk ke dalam negaranya (Chowdhury, 2019). Pemerintah Bangladesh dalam hal ini mengupayakan langkah-langkah untuk sekuritisasi keamanan nasional dan warga negara Bangladesh sendiri yang harus hidup berdampingan dengan para pengungsi. Penulisan ini membahas bagaimana upaya pemerintah Bangladesh dalam sekuritisasi keamanan nasional dan warga negara Bangladesh terkait keberadaan pengungsi Rohingya yang bernaung.

\section{METODE PENELITIAN}

Metode yang digunakan dalam penulisan ini adalah kualitatif untuk menggambarkan dan menjelaskan secara terperinci bagaimana upaya pemerintah Bangladesh dalam sekuritisasi keamanan nasional dan warga negara Bangladesh terkait permasalahan pengungsi Rohingya yang bernaung. Sumber data yang digunakan dalam penelitian ini diambil dari beberapa sumber seperti buku, artikel jurnal, dan website terpercaya, seperti yang disampaikan oleh (Cresswell, 2014) bahwa penelitian menggunakan metode kualitatif, sumber data yang digunakan bersifat multiple atau tidak hanya berasal dari satu sumber saja. Pencarian sumber data menggunakan kata kunci seperti Rohingya Refugees, National Security, Bangladesh, Securitization, kata kunci ini bertujuan untuk memperkecil lingkup pencarian untuk kemudian diolah dan menghasilkan suatu kesimpulan 
melalui analisa. Sumber data tersebut digunakan untuk membantu menjawab pertanyaan penelitian yaitu "bagaimana upaya pemerintah Bangladesh dalam sekuritisasi keamanan nasional dan warga negara terkait keberadaan pengungsi Rohingya?".

\section{PENDEKATAN TEORITIS}

Dalam mahzab Copenhagen dikatakan bahwa sebuah negara terancam keamanan nasionalnya apabila ancaman tersebut datang secara tiba-tiba, mempengaruhi, dan menurunkan kualitas hidup warga negara yang tinggal di dalamnya. Ancaman tersebut juga bersifat mempengaruhi sebuah negara untuk menjaga kualitas hidup normal warga negaranya. Pengertian ancaman dalam teori Copenhagen dikaitkan dengan sifat dari ancaman tersebut yang dapat membahayakan keselamatan individu (warga negara) seperti dari kekerasan fisik, terbatasnya akses terhadap kebutuhan pokok, adanya penyebaran penyakit menular, menurunnya kualitas lingkungan hidup, dan adanya penurunan kualitas hidup di dalam negara. Persepsi tentang keamanan dan ancaman menurut Copenhagen tidak hanya sebatas keamanan kedaulatan negara dan ancaman yang datang dari pihak eksternal, tetapi keamanan nasional negara bisa terancam apabila muncul fenomena-fenomena seperti; isu seputar mayoritas-minoritas; adanya penguasaan sumberdaya oleh kelompok tertentu yang mengakibatkan turunnya kredibilitas pemerintah negara dalam menangani; munculnya masalah deskriminasi dan kemiskinan (Hughes and Lai, 2011).

Dengan adanya bentuk-bentuk ancaman seperti diatas maka dapat mendorong sebuah negara untuk melakukan langkah pengamanan untuk melindungi keamanan nasional dan warga negaranya, dalam teori Copenhagen disebut dengan langkah sekuritisasi. Sekuritisasi diawali dengan adanya pernyataan (speech act) oleh tokoh tertentu yang memiliki peran penting (securitisizing actor) dan memiliki kekuasan atau jabatan tertentu dalam masyarakat seperti pejabat, tokoh masyarakat, dsb, yang menyampaikan suatu objek sedang menghadapi ancaman yang serius, objek yang dimaksud dapat berupa keamanan nasional atau individu (referent object), dan disampaikan di depan publik (target audience) agar ancaman tersebut dianggap sebagai peringatan (alert) yang dapat membahayakan keamanan nasional, sehingga membutuhkan penyelesaian secara tanggap (emergency response) dengan kebijakan di luar kebijakan normal (outside normal policies) (Hadiwinata, 2017). 


\section{ANALISIS DAN PEMBAHASAN}

Masalah-masalah yang dihadapi oleh pengungsi Rohingya di Bangladesh telah menimbulkan permasalahan-permasalahan yang juga harus dihadapi oleh pemerintah Bangladesh. Pemerintah Bangladesh harus memikirkan kebutuhan dan resiko yang ditimbulkan dengan adanya 180 ribu lebih keluarga Rohingya yang hidup di tenda-tenda penampungan. Sedangkan di sisi lain pemerintah harus menjaga kestabilan hidup warga negara Bangladesh yang berjumlah sekitar 163 juta jiwa (UNHCR, 2020 \& WorldBank, 2019).

Oleh sebab itu, pemerintah melakukan upaya sekuritisasi keamanan nasional dan kestabilan hidup warga negara Bangladesh. Pada bagian ini menjelaskan lebih lanjut dan terperinci mengenai komponenkomponen yang terdapat dalam teori sekuritisasi seperti siapa yang menjadi aktor sekuritisasi dalam permasalahan ini (securitisizing actor), kemudian apa saja bentuk-bentuk speech act yang diberikan oleh securitisizing actor terkait bentuk-bentuk ancaman yang dapat memebahayakan suatu objek (referent object), yang kemudian hal tersebut disampaikan di depan publik (audience), sehingga menjadi tanggap (alert) dan menjadikan apa yang disampaikan menjadi suatu hal yang harus ditangani secara serius (emergency response), meskipun dengan kebijakan di luar normal (outside normal policies).

\section{Pemerintah Bangladesh sebagai Securitisizing Actor}

Pada tahun 2017 saat krisis pengusiran etnis oleh Myanmar terhadap etnis Rohingya terjadi secara masif, Bangladesh merupakan salah satu negara yang menerima pengungsi Rohingya untuk masuk ke dalam negaranya (Rahman dan Dodul, 2020). Hal ini didasari oleh identitas budaya dan kepercayaan agama yang cukup kuat sehingga meyakini untuk menolong bagi yang membutuhkan pertolongan. Pada waktu itu Perdana Menteri Bangladesh Sheikh Hasina menyampaikan bahwa Bangladesh siap dan mampu untuk memberikan tempat tinggal sementara dan menyediakan pangan setidaknya bagi 700.000 pengungsi yang datang pada gelombang pertama kedatangan pengungsi Rohingya di Bangladesh (Dhaka'Tribune.com, 2017).

Tidak hanya pemerintah yang menerima kedatangan pengungsi Rohingya di Bangladesh, tetapi juga masyarakat yang bernaung di distrik Teknaf yang memiliki lokasi terdekat dengan salah satu jalur masuk para pengungsi di perbatasan Bangladesh dan Myanmar. Warga sekitar menerima kedatangan dengan baik, $86 \%$ dari masyarakat yang tinggal di distrik Teknaf ikut menyediakan 
makanan dan tempat tinggal sementara bagi para pengungsi (Sajjad, 2020).

Sikap pemerintah Bangladesh yang menerima dengan baik para pengungsi Rohingya di Bangladesh didasari oleh identitas negara dan moralitas yang tinggi terhadap kemanusiaan, ucap seorang akademisi dari American University School of International Service yang menekuni studi tentang Refugees and Forced Migration (Sajjad, 2020), pada saat itu pemerintah Bangladesh menganggap penyediaan tempat tinggal dan pangan berlangsung untuk jangka waktu sementara atau temporer dikarenakan menunggu kebijakan Myanmar untuk menerima kembali pemulangan etnis Rohingya ke negaranya. Namun hal tersebut tidak kunjung terlaksanakan dikarenakan sikap Myanmar yang pada waktu itu masih menolak pemulangan sejumlah pengungsi Rohingya di Bangladesh (Aljazeera, 2019).

Bangladesh termasuk dalam kategori negara lower middle income atau berpenghasilan menengah kebawah menurut World Bank, dan negara ini masih memiliki banyak kasus kemiskinan yang dialami oleh warga negaranya, di tahun 2020 persentase kemiskinan di Bangladesh naik menjadi $35 \%$ dari total populasi, sedangkan di tahun sebelumnya persentasi kemiskinan berada di angka 23.3\% (NewAgeBusiness, 2021; WorldBank, 2021). Dengan jumlah bantuan yang menurun dan permasalahan-permasalahan yang kian menumpuk dikarenakan keberadaan pengungsi Rohingya dalam kurun waktu panjang maka semakin menambahkan tekanan terhadap permasalahan yang sebelumnya sudah ada di Bangladesh. Permasalahan yang terjadi di tenda penampungan para pengungsi kemudian berubah menjadi permasalahan yang mengancam kestabilan keamanan nasional dan warga negara Bangladesh sendiri, oleh karena itu pemerintah Bangladesh dalam hal ini mau tidak mau melakukan langkah-langkah tegas yang dianggap dapat mencegah pelebaran permasalahan yang mengancam kestabilan nasional di Bangladesh sendiri. Pemerintah melakukan upaya sekuritisasi sebagai bentuk upaya penanganan permasalahan yang mengancam kestabilan negara, dalam hal ini pemerintah Bangladesh berperan sebagai aktor sekuritisasi.

Sebagai aktor sekuritisasi (securitisizing actor), maka pemerintah Bangladesh mengeluarkan sejumlah kebijakan seperti pembatasan akses terhadap para pengungsi yang bernaung di pengungsian; pembatasan akses terahadap badan yang ingin memberikan bantuan seperti Non Government Organization dan International Organization dikarenakan dapat melonggarkan pengawasan perbatasan lokal dan menimbulkan kecemburuan 
sosial; dan kebijakan pemulangan pengungsi Rohingya di Bangladesh dalam jangka waktu secepatnya (Crisis Group, 2019). Upaya sekuritisasi tersebut dilakukan oleh pemerintah Bangladesh untuk menekan permasalahan-permasalahan yang kian memuncak dengan adanya keberadaan pengungsi Rohingya di Bangladesh dalam jangka waktu panjang.

\section{Speech Act Pemerintah}

Bangladesh sebagai Bentuk Sekuritisasi Keamanan Nasional

Dalam beberapa kesempatan pemerintah Bangladesh melalui perwakilannya seperti Perdana Menteri dan Menteri Luar Negeri telah menyatakan keberatannya dalam menampung pengungsi Rohingya di Bangladesh untuk jangka waktu yang cukup lama. Hal ini disebabkan oleh permasalahan-permasalahan yang kian melebar di pengungsian seperti masalah yang mengancam perbatasan negara, kesehatan, dan sosial. Permasalahan ini telah menyentuh kestabilan nasional dan kehidupan warga negara Bangladesh. Sebelum kedatangan pengungsi Rohingya di Bangladesh, Bangladesh sudah memiliki permasalahannya sendiri, seperti masalah kemiskinan dan kelaparan yang dialami oleh 40 juta masyarakatnya baik dewasa maupun anak-anak. Menurut data yang diperoleh dari Global Hunger Index, anak-anak yang menderita busung lapar di Bangladesh mencapai angka 36,1\% pada tahun 2016 dan 2018 (Lihat pada gambar 1) (Global Hunger Index.org, 2019).

Gambar 1. Data Persentase Busung Lapar yang Dialami Anak-Anak di Bangladesh

\begin{tabular}{|c|c|c|c|}
\hline $\begin{array}{l}\text { GHI } \\
\text { BANGL }\end{array}$ & $\begin{array}{l}\text { INDICATOR } \\
\text { ADESH }\end{array}$ & VALUES & DIVISIONS, \\
\hline Division & $\begin{array}{c}\text { Child stunting } \\
\text { (\%) }\end{array}$ & $\begin{array}{c}\text { Child wasting } \\
\text { (\%) }\end{array}$ & $\begin{array}{c}\text { Child mortality } \\
\text { (\%) }\end{array}$ \\
\hline Barisal & 39.9 & 17.7 & 3.5 \\
\hline Chittagong & 38.0 & 15.6 & 5.0 \\
\hline Dhaka & 33.9 & 11.9 & 4.1 \\
\hline Khuina & 28.1 & 13.5 & 5.6 \\
\hline Rajshahi & 31.1 & 17.3 & 4.3 \\
\hline Rangpur & 36.0 & 17.7 & 3.9 \\
\hline Sylhet & 49.6 & 12.1 & 6.7 \\
\hline Total & 36.1 & 14.3 & 4.6 \\
\hline
\end{tabular}

Sumber: globalhungerindex.org

Keberadaan pengungsi Rohingya dengan permasalahannya dalam sudut pandang teori Copenhagen merupakan

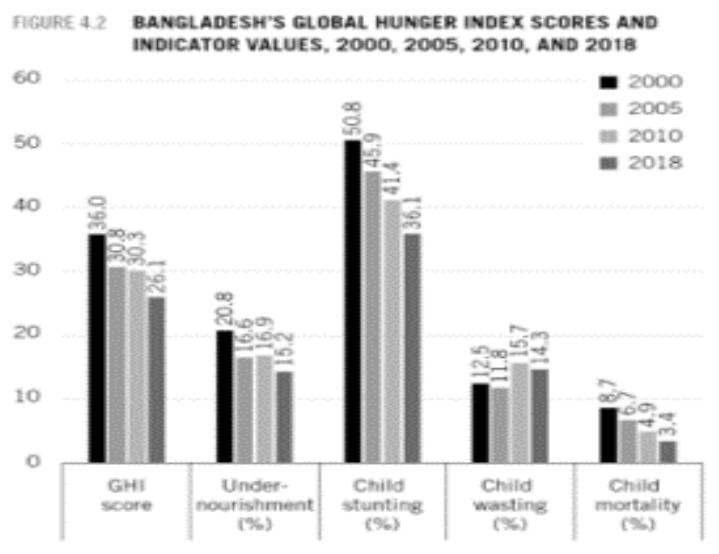

bentuk ancaman yang tidak hanya berhubungan dengan isu integritas teritorial negara tetapi juga 
menyangkut keselamatan individu warga negara dalam hal keterbatasan akses terhadap kebutuhan pokok, penyakit menular, degradasi kualitas lingkungan hidup dan kehidupan normal warga negara Bangladesh sendiri. Dikarenakan keberadaan pengungsi Rohingya di Bangladesh sudah menyentuh isu-isu seperti diatas maka pemerintah Bangladesh kewalahan dalam menjaga kestabilan hidup warga negara Bangladesh, jika permasalahan dibiarkan terus berlanjut dapat berdampak besar juga pada integritas teritori Bangladesh sendiri. Dalam hal ini pemerintah Bangladesh sebagai aktor sekuritisasi yang memiliki kuasa dan pengaruh menyampaikan keberatannya dalam bentuk speech act untuk menyuarakan adanya ancaman serius yang berbahaya jika dibiarkan permasalahan terus berlanjut.

Pada tahun 2019 Menteri Luar Negeri (A.K. Abdul Momen) dan Sekretaris Luar Negeri Bangladesh pada masa itu (Shahidul Haque) menyampaikan keberatannya kepada United Nations untuk tidak lagi menerima berapapun jumlah pengungsi Rohingya yang ingin masuk ke Bangladesh dan mendesak Myanmar untuk segera merepatriasi pengungsi Rohingya yang ada di Bangladesh meskipun secara berkala, keberatan ini disampaikan dengan alasan akomodasi biaya perbulan untuk membiayai pengungsi Rohingya sangat besar yaitu 300 juta US dollar. Pemerintah Bangladesh melalui perwakilannya juga menyampaikan bahwa permasalahan pengungsi Rohingya di Bangladesh tidak dapat diselesaikan oleh satu negara melainkan membutuhkan respon global terkait penyelesaian dan solusinya. Keberatan yang disampaikan oleh pemerintah Bangladesh kepada United Nations adalah speech act yang bertujuan untuk menyatakan permasalahan keberadaan pengungsi Rohingya di Bangladesh adalah permasalahan yang memiliki tingkat urgensi yang harus segera ditangani dan bukan lagi sebagai isu politik biasa tetapi sudah menyangkut keamanan nasional dan wraga negara asli Bangladesh sendiri (Papri, 2019; Perdana, 2019).

\section{Sekuritisasi Warga Negara Asli Bangladesh sebagai Referent Object}

Referent object dalam pandangan Copenhagen dapat diartikan sebagai suatu objek yang sedang menghadapi ancaman serius dan berhubungan dengan keamanan Individu dan nasional, dalam konteks ini adalah keamanan nasional dan warga negara asli Bangladesh. Berbagai macam permasalahan timbul dengan adanya keberadaan pengungsi Rohingya di Bangladesh dalam jangka waktu 
panjang, tidak hanya jenis permasalahan baru tetapi juga memperumit permasalahan yang sebelumnya sudah ada di Bangladesh. Permasalahan-permasalahan yang ada menyangkut beberapa aspek penting yang langsung berhubungan dengan keamanan nasional dan warga negara Bangladesh, diantaranya adalah; permasalahan seputar kejahatan transnasional; masalah kesehatan dan lingkungan hidup; dan masalah sosialekonomi.

Bentuk-bentuk permasalahan tersebut menjadi ancaman bagi kestabilan nasional Bangladesh sehingga menjadi faktor pendorong bagi pemerintah mengambil langkah sekuritisasi. Berikut dijelaskan macam-macam ancaman yang dimaksudkan:

Pertama, keterkaitan Pengungsi Rohingnya dengan Kejahatan Transnasional di Wilayah Perbatasan Bangladesh. Kejahatan Transnasional menjadi salah satu bentuk kejahatan yang sudah ada sebelumnya namun diperumit dengan keberadaan pengungsi Rohingya yang ikut terlibat di dalamnya. Kejahatan Transnasional yang berkaitan dengan pengungsi Rohingya di Bangladesh banyak terjadi di wilayah perbatasan pengungsian (Ullah, 2011). Pengungsi Rohingya dijadikan target bagi pihak-pihak pelaku kejahatan untuk melancarkan kegiatan ilegal mereka, diantaranya adalah (1) penyebaran paham
Radikalisme, Jaringan Teroris, dan Penyelundupan Senjata Api.

Salah satu wilayah pengungsian paling besar untuk para pengungsi Rohingya di Bangladesh adalah di distrik Cox's Bazar. Wilayah ini terletak di Tenggara Bangladesh dan bersinggungan langsung dengan wilayah pantai dan laut. Cox's Bazar berbatasan dengan perairan Myanmar dan Thailand, wilayah ini menjadi tujuan bagi para pelaku kejahatan transnasional untuk melakukan berbagai kegiatan penyelundupan barang-barang terlarang seperti persenjataan, obat-obatan terlarang (narkoba), hingga perdagangan manusia. Keterbatasan akses terhadap kebutuhan pokok menjadi salah satu alasan bagi para pengungsi untuk terlibat dalam kegiatan seperti ini untuk sekedar mendapatkan imbalan. Permasalahan penyebaran paham radikalisme dan jaringan teroris sebelumnya memang sudah terjadi di Bangladesh dan menjadi salah satu agenda kerja pemerintah untuk mengatasinya sejak tahun 1992. Namun dengan masuknya jumlah pengungsi yang banyak dan dalam kondisi trauma, stres serta mudah terpengaruh membuat para pengungsi menjadi target bagi para penyebar ajaran radikal dan teroris untuk menyusupi pikiran mereka (Ullah, 2011). 
Kegiatan yang dilakukan oleh para penyebar ajaran ini adalah menyusupi wilayah pengungsian para pengungsi Rohingya dan melakukan pencucian otak para pengungsi untuk disusupi ajaran sesat, hingga kemudian para pengungsi yang sudah berhasil dicuci pikirannya ditawari untuk bergabung menjadi salah satu anggota ekstrimis ini. Jaringan teroris ini memiliki hubungan dengan jaringan teroris kelas kakap seperti Al-Qaeda dan juga jaringan teroris lokal yang juga membiayai operasi kelompok ini. Para pengungsi yang sudah berhasil tercuci pikirannya mulai menjalankan aksinya untuk mempengaruhi pengungsi lainnya, shingga penyebaran paham radikal dan terorisme semakin berkembang dan meluas di kalangan para pengungsi, hal ini sangat berbahaya jika dibiarkan terus berlanjut, terutama sangat membahayakan keamanan nasional (Rahman, 2010).

Selain paham radikal dan terorisme, para penyebar ajaran ini juga meloloskan aksi penyelendupan senjata api yang dibawa oleh Pemberontak dari Myanmar dan Thailand melalui Chittagong Hills Tract yaitu perbatasan Bangladesh dengan India dan Myanmar. Perbatasan ini terletak di wilayah Tenggara Bangladesh. Penyelundupan senjata api dilakukan melalui wilayah ini dikarenakan wilayah perbatasan lebih mudah disusupi, didukung dengan bantuan para pengungsi yang bekerjasama dah sudah terpengaruh oleh paham radikal. Tidak hanya pengungsi yang sudah masuk menjadi anggota tetapi para pengungsi yang tidak punya pilihan dikarenakan memiliki kebutuhan (memiliki anak dan isteri) melihat peluang ini sebagai cara singkat untuk mendapatkan imbalan (Bashar, 2012); penyelundupan obat-obat-an Terlarang.

Para pengungsi juga terlibat dengan kegiatan penyelundupan obatobatan terlarang atau narkoba yang sebelumnya juga sudah menjadi permasalahan bagi pemerintah Bangladesh. Sebanyak 2,5 juta anak di Bangladesh tercatat sebagai pecandu dan pengguna aktif narkoba (AsiaPasific, 2018). Bisnis penyelundupan obat-obatan terlarang di Bangladesh menjadi bisnis yang sangat menguntungkan karena jumlah pecandu narkoba di Bangladesh memang sudah cukup tinggi dan permintaan terhadap narkoba juga semakin meningkat, selain itu Bangladesh juga menjadi salah satu negara tujuan bagi para penjual narkoba untuk meraih keuntungan besar, sehingga para pemasok dan pendistributor melihat keberadaan para pengungsi sebagai peluang yang akan mempermudah kegiatan bisnis mereka. Secara otomatis dengan 
adanya para pengungsi maka penjagaan di wilayah perbatasan menjadi melonggar karena perhatian dan konsentrasi para petugas keamanan menjadi terpecah (Ullah, 2011).

Jenis narkoba yang paling diminati dan diselundupkan di Bangladesh adalah Methamphetamine Pills yang berjenis sabu-sabu dan dikenal dengan nama populer Yaba atau Madness Drug. Narkoba jenis ini diselundupkan dari Myanmar dan para pengungsi menjadi penyelundup yang memudahkan narkoba masuk ke Bangladesh. Alasan kebutuhan pokok dan membutuhkan pekerjaan menjadi penyebab mengapa para pengungsi mau terlibat dalam kejahatan ilegal seperti ini. UN melalui United Nations High Comissioner for Refugees (UNHCR) sebenarnya telah memberikan bantuan kebutuhan pokok dan meberikan pekerjaan pada para pengungsi, namun dengan banyaknya jumlah pengungsi yang ada bantuan yang diberikan harus diusahakan merata sehingga porsi bantuan per kepala menjadi berkurang. Begitu juga dengan pekerjaan yang diberikan oleh UNHCR, upah yang diberikan sangat kecil dan tidak mencukupi kebutuhan para pengungsi (Banarjee, 2019). Pemerintah Bangladesh juga tidak bisa berbuat banyak, selain mengatasi permasalahan para pengungsi, pemerintah Bangladesh utamanya harus memikirkan kehidupan warga negara Bangladesh terlebih dahulu, permasalahan kebutuhan pokok dan penyedian lapangan pekerjaan juga masih menjadi permasalahan yang juga dialami oleh penduduk Bangladesh.

Kedua, masalah Kesehatan dan Lingkungan. Populasi pengungsi Rohingya di Bangladesh yang melebihi angka 1 juta jiwa menyebabkan masalah kesehatan juga muncul sebagai masalah yang harus diperhatikan secara serius (UNHCR, 2019). Keberadaan pengungsi Rohingya di Bangladesh hingga saat ini bisa dikatakan sudah memasuki kurun waktu yang cukup lama sehingga permasalahan menyangkut kesehatan juga semakin rumit. Utamanya permasalahan ini terjadi di pengungsian yang paling banyak menampung dan padat manusia seperti di Camp Cox's Bazar. Berikut macam-macam penyakit yang timbul di dalam pengungsian dan mengancam kesehatan warga negara asli Bangladesh yang tinggal di sekitar daerah pengungsian, diantaranya: (1) penyakit Mental yang Diderita Para Pengungsi Akibat Trauma dan Stres

Akibat Pengusiran etnis yang melibatkan kekerasan oleh Myanmar terhadap etnis Rohingya menyebabkan rasa trauma dan stres mendalam bagi sebagain besar para pengungsi, tidak terkecuali pengungsi yang bernanung di Bangladesh. Trauma dan stres 
semakin diperparah dengan terbatasnya akses dan pergerakan para pengungsi, bukan tanpa sebab, pembatasan akses yang dilakukan oleh pemerintah Bangladesh tidak bertujuan untuk memperburuk kondisi para pengungsi, tetapi pemerintah tidak memiliki pilihan lain dan meminimalisir terjadinya permasalahan lain jika akses pengungsi dibebaskan. Pada awalnya pengungsi juga mengalami kesulitan dengan beradaptasi terutama dengan bahasa atau local ideoms, di Bangladesh sendiri menggunakan bahasa Bengali, sedangkan para pengungsi menggunakan bahasa Bamasa. Bantuan yang diberikan oleh organisasi internasional juga biasanya diinstruksikan dengan menggunakan bahasa inggris, dan sebagaian besar para pengungsi tidak bisa berbahasa asing, sehingga menambah faktor stres yang diderita oleh para pengungsi (Riley, 2017).

Akibat keterbatasan akses terhadap kebutuhan pokok, bantuan, dan akses lainnya maka para pengungsi yang tidak tahan terhadap tekanan menjadi berlaku agresif dan melukai pengungsi lain, begitupun dengan para pengungsi yang lainnya, stres dan trauma yang diderita membuat mereka lebih sensitif dan mudah terpancing emosinya. Kurangnya fasilitas kebersihan seperti kakus juga menambah stres yang dialami oleh pengungsi, terutama para pengungsi perempuan, mereka terpaksa harus buang air kecil atau besar di ruang terbuka dikarenakan kondisi padat pengungsi tidak sebanding dengan jumlah kakus yang ada. Ada sekitar 100 orang pengungsi per harinya yang harus dilarikan ke rumah sakit akibat melukai diri sendiri karena tidak tahan dengan kondisi di pengungsian yang tidak menentu begitupun hidup mereka (UNHCR, 2018). Untuk menangani permasalahan ini pemerintah Bangladesh harus mengeluarkan anggaran untuk kesehatan para pengungsi baik obatobatan dan tenaga medis, di lain sisi masih banyak penduduk asli Bangladesh yang masih membutuhkan bantuan medis dengan berbagai keluhan penyakit (Riley, 2017; White, 2017); (2) penyakit Menular seputar Pencernaan Akibat Kurangnya Pangan dan Air Bersih.

Pada awal kedatangan para pengungsi Rohingya di Bangladesh pemerintah Bangladesh menunjukan sikap keterbukaan dan memberikan pertolongan bagi para pengungsi begitupun juga bantuan banyak datang dari organisasi internasional atau jenis bantuan internasional maupun domestik lainnya terus berdatangan untuk sekedar memenuhi kebutuhan dasar para pengungsi. Pemerintah Bangladesh juga sudah menganggarkan dana untuk 
mengakomodasi kebutuhan pangan dan air bersih untuk para pengungsi, namun seiring berjalannya waktu pemerintah kewalahan untuk menganggarkan dana yang begitu besar untuk memenuhi seluruh kebutuhan para pengungsi, mulai dari kebutuhan pangan dan air bersih sampai masalah kesehatan, begitupun juga jumlah bantuan yang menurun.

Pemerintah Bangladesh tidak lagi sanggup untuk memenuhi kebutuhan para pengungsi Rohingya di Bangladesh karena pemerintah juga harus memikirkan kestabilan pengeluaran nasional dan permasalahan warga negara Bangladesh sendiri. Keberadaan pengungsi Rohingya yang bernaung di Bangladesh dengan begitu padatnya dan berbagai kebutuhan yang tidak terpenuhi mengakibatkan para pengungsi menderita penyakit yang mudah menular dan berbahaya jika dibiarkan terus menerus. Salah satu penyakit yang berkembang pesat dan luas adalah penyakit seputar pencernaan atau Oral Cholera yang disebabkan kurangnya nutrisi, air bersih, dan lingkungan yang bersih (Qadri, 2018).

\section{Penyakit Oral Cholera sangat} berbahaya dan sangat mudah menular terutama melalui saluran air yang tidak terorganisir dengan baik. Wilayah pengungsian yang padat pengungsi menyebabkan sistem perairan air bersih dan penyediaanya menjadi hal yang tidak mudah diwujudkan oleh pemerintah Bangladesh. Penggunaan air bersih sangat dibutuhkan oleh pengungsi Rohingy, dibutuhkan 16 juta liter air per hari, namun pemerintah sudah berusaha semaksimal mungkin dan hanya bisa menyediakan kebutuhan air 30\% dari jumlah tersebut kepada para pengungsi, alhasil pengungsi yang tidak mendapatkan air bersih harus menggunakan air kotor yang berlumpur untuk memenuhi kebutuhan air bersih (UNICEF, 2018). Di lain sisi pemerintah juga harus menyediakan air bersih bagi warga negara Bangladesh yang tinggal disekitar wilayah pengungsian, namun yang terjadi warga lokal harus rela berbagi air bersih dengan para pengungsi (Islam dan Nuzhath, 2018; UNICEF, 2018).

Berbagai upaya dilakukan oleh para pengungsi untuk mendapatkan air bersih seperti menggali tanah untuk memunculkan sumber air, namun permasalahannya adalah lingkungan yang ditinggali oleh para pengungsi sangat padat, dan sudah banyak juga pengungsi yang lain mengupayakan hal yang sama. Jika terdapat sumber air bersih seperti sungai atau aliran air juga tidak bisa terjamin kebersihannya, karena sumber air tersebut berdekatan dengan bekas galian-galian para pengungsi untuk membuang kotoran 
dari tubuh. Seperti yang terjadi di Camp Cox's Bazar, salah satu tempat sumber air bersih jaraknya hanya 10 meter di bawah rimbun pohon bambu, rimbuh pohon tersebut juga sudah biasa digunakan oleh para pengungsi untuk membuang kotoran dengan sistem penggalian. Sehingga bisa dikatakan sumber air yang dikonsumsi oleh para pengungsi memang sudah tercemar oleh bakteri-bakteri dari kotoran-kotoran yang berasal dari para pengungsi sendiri (Chan, 2017).

Penyakit Oral Cholera memiliki gejala seperti buang-buang air atau diare, dan sifat dari penyakit ini menular dengan cepat melalui lingkungan hidup seperti sistem perairan (water-borne), tidak hanya pengungsi yang terjangkit penyakit ini tetapi 135.000 warga negara asli Bangladesh yang tinggal disekitar wilayah pengungsian seperti di Cox Bazar juga ikut terjangkit penyakit Oral Cholera, hingga tahun 2019 jumlah kasus yang terjangkit penyakit ini dari penduduk asli sebanyak 32 kasus (WHO, 2018; WHO, 2019). Dalam pandangan Copenhagen dikatakan bila suatu ancaman dalam konteks ini adalah penyakit menular yang ditimbulkan dari keberadaan Pengungsi Rohingya di Bangladesh yang datang secara tiba-tiba kemudian bermukim dalam jangka waktu cukup lama telah mempengaruhi kualitas hidup warga negara Bangladesh maka dapat membahayakan keamanan nasional dan kehidupan normal warga negara Bangladesh sendiri; (3) bantuan vaksin yang Tidak Mencukupi.

Permasalahan dengan munculnya penyakit seperti diatas mendapatkan perhatian dari WHO (World Health Organization). WHO bekerja sama dengan ICG (International Coordinating Group) dan pemerintah Bangladesh untuk menangani masalah penyebaran penyakit Kolera dan Diare dengan pemberian vaksin OCVs (Oral Cholera Vaccines). Vaksin ini didanai oleh Gavi Alliance untuk diberikan secara gratis kepada wilayah-wilayah yang di dalamnya terdapat kondisi Humanitarian Eemergency, seperti yang dialami oleh para pengungsi Rohingya di Bangladesh. Pemberian vaksin utamanya dilakukan di wilayah yang paling padat manusia seperti di Cox's Bazar. Para pengungsi yang masuk ke Bangladesh datang dalam kondisi kesehatan yang juga kurang baik akibat kelelahan, trauma, dan stress, begitu juga keadaan yang dialami oleh anakanak pengungsi Rohingya yang mengalami kondisi berat badan dibawah standar karena belum mendapatkan vaksin pada saat mereka lahir (Qadri, 2018).

Sehubungan dengan adanya penyebaran penyakit Oral Cholera yang penyebarannya sangat cepat maka pemerintah Bnagladesh dan WHO mengambil langkah penanganan dan 
pencegahan dengan memberikan vaksin OCV. Sebanyakan 900.000 dosis diberikan kepada para pengungsi Rohingya dan penduduk Bangladesh yang tinggal disekitar wilayah pengungsian untuk mencegah penyebaran penyakit semakin meluas (WHO, 2017). Dosis sebanyakan ini merupakan dosis maksimal yang dapat dianggarkan oleh WHO sebagai tindak penanganan dan pencegahan penyebaran penyakit kolera dan diare di Bangladesh. Satu dosis diberikan kepada orang dewasa, dan dua dosis diberikan kepada anak-anak berusia 1 4 tahun, pemberian 1 dosis untuk orang dewasa dimaksudkan untuk memaksimalkan pemberian dosis kepada anak-anak, karena orang dewasa dianggap lebih memiliki ketahanan terhadap jangkitan penyakit kolera dan diare. Anak-anak dianggap lebih membutuhkan dosis yang lebih banyak karena secara alami tubuhnya belum sempurna memproduksi imun yang lebih kuat terhadap penyakit diare atau kolera. Ketentuan pemberian dosis ini juga dimaksudkan sebagai strategi agar vaksin OCV ini bisa diberikan secara merata kepada seluruh pengungsi Rohingya meskipun dengan ketentuan dosis yang seharusnya sama antara anak-anak dan dewasa, namun dengan adanya keterbatasan yang diakibatkan begitu banyaknya pegungsi yang harus menerima vaksin maka ditetapkan strategi tersebut (Summers at all, 2018).

Dalam hal tindakan penanganan dan pencegahan ini juga menimbulkan permasalahan baru, bagi orang dewasa yang menerima satu dosis maka sedikit banyak ada kemungkinan untuk terjangkit kolera atau diare lebih besar, karena seharusnya menerima dua dosis. Permasalahan lainnya yang meuncul adalah, adanya fakta bahwa ada sejumlah lonjakan angka pengungsi yang pada saat kegiatan kampanye vaksin berlangsung belum menerima vaksin atau hanya mendapat satu dosis vaksin diikhawatirkan akan memunculkan ancaman atau potensi adanya penularan penyakit diare dan kolera yang lebih besar lagi di waktu mendatang. Sifat dari penyakit kolera dan diare ini tidak hanya disebabkan oleh karena keadaan air bersih yang kurang, fasilitas sanitasi yang tidak memadai, atau konsumsi pangan yang kurang bernutrisi, tetapi penyebaran penyakit ini juga diakibatkan oleh cuaca yang tidak menentu dan menimbulkan fenomena seperti banjir atau angin puting beliung. Kedaan cuaca yang tidak menentu semakin meningkatkan potensi gelombang penyebaran penyakit kolera dan diare yang lebih besar lagi (Syed at al, 2016).

Bagi para pengungsi yang sudah menerima vaksin dengan dua dosis atau satu dosis, juga tidak menjamin tubuh meraka imun dari penyakit 
kolera dan diare, ada kemungkinan mereka juga akan terjangkit apabila kualitas air bersih yang mereka konsumsi tidak membaik, begitupun juga kualitas pangan dan lingkungan hidup yang masih di bawah standar. Sangat memungkinkan penyebaran penyakit ini dapat membahayakan kualitas kesehatan penduduk asli Bangladesh di kemudian hari (Syed at al, 2016); (4) fasilitas kesehatan yang tidak memadai.

Permasalahan fasilitas kesehatan yang tidak sepadan dengan jumlah pasien yang melonjak karena penyakit kolera, diare, infeksi luka, dsb yang diderita para pengungsi Rohingya menyebabkan fasilitas kesehatan seperti rumah sakit, klinik, dan pospos kesehatan darurat penuh sesak dengan para pasien pengungsi. Pasien yang masuk dalam fasilitas kesehatan seperti rumah sakit tidak hanya dikarenakan alasan sakit, tetapi juga ada sebagian pengungsi yang sengaja melukai diri sendiri agar bisa dirawat dalam fasilitas kesehatan. Begitupun dengan para pasien pengungsi yang sebelumnya sudah berada dalam fasilitas kesehatan menolak untuk dinyatakan sembuh dan bisa keluar dari fasilitas kesehatan. Hal ini dikarenakan para pasien pengungsi merasa lebih dimanusiakan jika berada dalam fasilitas kesehatan, makan, minum, tempat tinggal, dan fasilitas kebersihan lebih terjamin di dalam fasilitas kesehatan ketimbang di wilayah pengungsian. Kondisi seperti ini menyebabkan fasilitas kesehatan seperti rumah sakit nasional menjadi tempat yang nyaman bagi warga negara asli Bangladesh untuk berobat menjadi tidak kondusif karena dipenuhi oleh pasien pengungsi Rohingya (Kate, 2017).

Masalah yang ditimbulkan dari keadaan seperti ini adalah anggaran pemerintah Bangladesh yang terus meningkat untuk anggaran fasilitas kesehatan gratis bagi para pengungsi Rohingya dan stok obat-obatan menjadi terkuras. Obat-obat-an menjadi salah satu kebutuhan penting bagi pasien sakit, terutama warga negara asli Bangladesh, warga negara asli dalam keadaan seperti ini harus berbagi fasilitas kesehatan dengan banyaknya para pasien pengungsi, berikut juga warga negara asli harus bersabar menunggu stok obat yang dibutuhkan karena digunakan untuk para pasien pengungsi Rohingya (Kate, 2017).

Ketiga, Masalah Degradasi Lingkungan Hidup. Pengusiran etnis Rohingya dari Myanmar di tahun 2017 secara besar-besaran meningkatkan lonjakan angka pengungsi yang harus ditampung oleh Bangladesh. Hal ini menyebabkan wilayah pengungsian seperti Cox's Bazar sebagai salah satu wilayah pengungsian terbesar harus dipenuhi oleh pengungsi yang datang 
dalam jumlah besar. Tenda-tenda pengungsian yang dibangun tidak mampu menampung seluruh pengungsi di dalamnya. Sebagian pengungsi tidak mendapatkan tempat bernaung, sehingga mereka tidak memiliki pilihan selain membuat tenda penampungan sendiri dengan menggunakan alat-alat yang tersedia. Para pengungsi menempati lahan disekitaran wilayah pengungsian dengan memotong pohon-pohon seperti bambu dan digunakan sebagai pondasi untuk membangun tempat bernaung, para pengungsi juga menggunakan kain atau plastik bekas sebagai atap. Pada dasarnya di sekitaran wilayah pengungsian seperti di Cox's Bazaar merupakan wilayah resapan air, sumber pangan, dan obatobatan herbal tradisional bagi penduduk asli Bangladesh yang tinggal di wilayah tersebut (Mukul at al, 2019).

Pengungsi Rohingya di wilayah tersebut tidak hanya membangun tempat untuk bernaung tetapi juga memanfaatkan sumber daya alam yang ada untuk memenuhi kebutuhan hidup. Permasalahannya adalah sumber daya yang terdapat di wilayah pengungsian penggunaanya melebihi batas yang seharusnya, sebelum para pengungsi Rohingya bernaung, hanya masyarakat asli sekitar yang memanfaatkan sumber daya tersebut. Wilayah pengungsian Rohingya di Cox's Bazaar sudah mengalami perluasan lebih dari 2000 ha, luas tersebut merupakan luas hutan yang harus dilapangkan untuk menampung para pengungsi. Perluasan tersebut menimbulkan permasalahan bagi habitat gajah dan kebutuhan sumber daya masyarakat asli untuk memenuhi kebutuhan sehari-hari. Perluasan lahan tersebut menimbulkan konflik antara pengungsi Rohingya dan warga asli Bangladesh yang bergantung dengan sumber kayu bakar yang terdapat di hutan wilayah pengungsian. Permasalahan lain yang timbul akibat perluasan lahan ini adalah masalah bencana alam yang diakibatkan penggundulan wilayah hutan, dengan ditebanginya pepohonan dan padatnya penduduk yang bernaung maka wilayah tersebut menjadi rawan longsor yang juga berimbas pada sumber air bersih, irigasi, dan cadangan air dalam tanah (Mukul at al, 2017).

Keempat, masalah ekonomi dan Sosial. Kondisi pengungsi Rohingya yang putus asa dan tidak memiliki tujuan di dalam wilayah pengungsian yang sudah cukup lama membuat mereka tidak memiliki pilihan lain selain mencari kesempatan untuk mencari penghasilan untuk bertahan hidup. Bantuan yang diberikan oleh Organisasi Internasional dan Lembaga Swadaya masyarakat seperti UN, WHO, UNHCR tidak dapat mencukupi kebutuhan hidup mereka. 
Contohnya seperti kebutuhan makan yang merupakan kebutuhan pokok, setiap pengungsi hanya mendapatkan jatah makan satu kali sehari. Para pengungsi rela untuk membahayakan diri mereka sendiri hanya untuk sekedar mendapatkan upah dalam bentuk makanan. Di dalam wilayah pengungsian peraturan menetapkan bahwa pengungsi tidak diperbolehkan untuk keluar masuk wilayah pengungsian tanpa izin dengan alasan apapun, apalagi untuk mencari pekerjaan. Secara hukum, para pengungsi Rohingya tidak memiliki hak untuk mencari pekerjaan di Bangladesh, namun hal yang dilakukan oleh para pengungsi adalah mencuri kesempatan untuk keluar dari wilayah pengungsian atau menjual produk buatan mereka sendiri di pasar lokal (Crabtree, 2010).

\section{Para pengungsi Rohingya} menggunakan kesempatan dengan memasang upah diri rendah, namun hal ini justru membuat standar upah buruh di sekitar wilayah pengungsian seperti Cox's Bazaar, Kutupalong, dan Nayapara bagi warga lokal menjadi tidak stabil. Dengan menawarkan upah kerja yang rendah, otomatis membuat pabrik atau perekrut lebih memilih pengungsi Rohingya ketimbang penduduk asli. Sebanyak 88\% persen pengungsi Rohingya laki-laki dewasa tercatat menjadi buruh harian dengan menerima bayaran yang sangat kecil yaitu $\$ 0.70$, bahkan tidak cukup untuk memberi makan satu keluarga, mereka berani mengambil resiko dengan bekerja tanpa jaminan hukum atau undang-undang yang melindungi. Keadaan seperti menimbulkan persaingan antara pengungsi Rohingya yang mencari pekerjaan dan penduduk asli Bangladesh yang bekerja sebagai buruh (Milton at al, 2017).

Secara tidak langsung para pengungsi Rohingya mengambil kesempatan bagi warga negara asli Bangladesh untuk mencari lapangan pekerjaan. Di dareah penampungan seperti Cox's Bazaar, Kutupalong, Nayapara kebanyakan dari penduduk asli disana tergolong masyarakat miskin yang sangat bergantung dengan pekerjaan sebagai buruh dan sumber daya alam yang terdapat di hutan untuk memenuhi kebutuhan mereka atau sebagai sumber pendapatan. Kondisi Bangladesh yang menampung pengungsi Rohingya dalam jangka panjang dan tanpa rencana ke depan membuat penduduk asli, terutama yang tinggal dekat dengan penampungan mengkhawatirkan keadaan perekonomian mereka yang harus bersaing dengan pengungsi, belum lagi masalah keterbatasan akses terhadap kebutuhan pokok dikarenakan hutan yang menjadi sumber telah rusak, dan meningkatnya angka kriminalitas. Penduduk Bangladesh sendiri merasa mereka 
adalah rakyat yang miskin dan masih membutuhkan banyak bantuan dari pemerintah, dan merekalah yang harus lebih diperhatikan, bukan para pengungsi Rohingya (Crabtree, 2010).

Permasalahan kebutuhan ekonomi juga mendorong munculnya masalah sosial lain antara pengungsi Rohingya dan warga negara asli Bangladesh. Beberapa dari pengungsi terpaksa memalsukan surat-surat atau dokumen seperti ijin tinggal, ijin bekerja, kartu penduduk sementara, hingga surat pernikahan palsu. Sebagian pegungsi melakukan caracara seperti diatas sebagai upaya untuk mendapatkan kehidupan yang lebih baik, salah satu contohnya adalah pernikahan ilegal yang dilakukan oleh sebagian perempuan pengungsi untuk tujuan mendapatkan kehidupan yang lebih layak, yaitu dengan menikahi penduduk asli Bangladesh, hal ini dilakukan atas dasar pemikiran menikah secara ilegal lebih baik dibandingkan terus bertahan hidup di dalam pengungsian dengan ketidakjelasan. Hal ini menjadi berbahaya karena pengungsi Rohingya yang menikah dengan warga negara Bangladesh tidak dilindungi oleh hukum atau perundang-undangan, mengingat pengungsi Rohingya masih belum memiliki status kewarganegaraan yang jelas. Banyak juga dari sebagian perempuan pengungsi Rohingya terpaksa menjual diri atau terlibat dengan kegiatan prostitusi untuk mendapatkan penghasilan (Crabtree, 2010).

\section{Upaya Pemerintah Bangladesh Meningkatkan Status Darurat Penanganan Pengungsi Rohingya}

Dalam pandangan Copenhagen, dijelaskan tahapan atau proses sekuritisasi dapat dilakukan sebuah negara dalam kondisi darurat yang disebabkan oleh ancaman atau permasalahan yang menyentuh keamanan nasional dan warga negara di dalamnya. Dengan adanya permasalahan-permasalahan yang menyangkut aspek kestabilan nasional seperti; kejahatan transnasional dalam bentuk penyelundupan senjata api dan obat-obatan terlarang; kesehatan dan lingkungan; dan ekonomi-sosial yang terjadi di Bangladesh dengan keberadaan pengungsi Rohingya dalam jangka waktu yang cukup panjang, telah mendorong pemerintah Bangladesh untuk menyampaikan speech act atau keberatannya sebagai bukti bahwa negara sudah tidak mampu lagi untuk menangani permasalahan yang ada secara individual, sehingga harus mengeluarkan berbagai macam peraturan dan kebijakan untuk sekuritisasi keamanan nasional dan warga negara di dalamnya yang dalam pandangan Copenhagen dianggap sebagai referent object. 
Keberatan yang disampaikan oleh pemerintah Bangladesh kepada United Nations bertujuan untuk mendapatkan perhatian internasional sebagai target audience yang dapat mengerti kesulitan dan permasalahan yang dihadapi oleh Bangladesh, tidak hanya UN yang menjadi target audience Bangladesh, tetapi juga diharapkan negara lain yang mau ikut membantu dengan menerima sebagian pengungsi Bangladesh di negaranya, keberatan yang disampaikan ini juga bertujuan untuk mendapatkan dukungan global akan solusi atau penyelesaian permasalahan pengungsi berdasarkan kebijakan yang dibuat oleh pemerintah Bangladesh sendiri (alert) (Crisis Group, 2019).

\section{Kebijakan Emergency Response Pemerintah Bangladesh terkait Pengungsi Rohingya}

Upaya yang dilakukan oleh pemerintah Bangladesh untuk menangani permasalahan pengungsi seperti yang sudah dijelaskan diatas agar tidak semakin parah dan meluas adalah dengan membatasi akses para pengungsi baik mobilisasi, komunikasi, dan kebutuhan sosial para pengungsi (Crisis Group, 2019). Pemerintah Bangladesh meningkatkan pengawasan di sekitar wilayah pengungsian dengan menambah personil keamanan dan kamera pengawasan untuk menekan kriminalitas yang terjadi di pengungsian seperti kejahatan transnasional yang terjadi dan sangat membahayakan keamanan nasional dan warga negara asli Bangladesh. Pemerintah juga tidak bisa menyediakan kebutuhan sosial para pengungsi seperti lapangan pekerjaan, pendidikan, dan jaminan kesehatan, bukan tanpa alasan, keberadaan pengungsi Rohingya di Bangladesh sudah memasuki kurun waktu yang panjang sehingga pemerintah tidak bisa terus mengakomodasi kebutuhan para pengungsi, melainkan harus lebih memperhatikan kestabilan negara dan kehidupan warga negara Bangladesh.

Pemerintah Bangladesh juga tidak ingin menjadikan permasalahan pengungsi ini sebagai masalah yang membutuhkan solusi yang bersifat jangka panjang seperti dengan membangun pengungsian yang lebih layak, tetapi sebaliknya pemerintah Bangladesh menetapkan isu pengungsi ini sebagai permasalahan jangka pendek yang juga mebutuhkan solusi segera yaitu dengan memulangkan segera pengungsi Rohingya untuk kembali ke Myanmar.

Namun pada saat ini kondisi Myanmar sendiri sedang tidak stabil dikarenakan adanya kudeta militer yang kembali terjadi oleh Junta Militer yang tidak terima dengan hasil Pemilihan Umum yang memenangkan partai National League for Democracy 
yaitu kubu Presiden Win Myint dan Aung San Suu Kyi. Dengan adanya isu ini di Myanmar maka rencana pemulangan atau repatriasi sebagian pengungsi Rohingya secara berkala yang direncanakan bada Bulan Juni 2021 menjadi hal yang tidak memiliki kepastian (BBC, 2021). Dengan adanya hal ini maka pemerintah Bangladesh terpaksa mengambil langkah kebijakan sebagai upaya untuk sekuritisasi keamanan nasional dan warga negara Bangladesh, langkah yang dimaksudkan adalah memindahkan 1.600 pengungsi Rohingya pada bulan Desember 2020 ke Bhahsan Char yang merupakan salah satu pulau yang dimiliki oleh Bangladesh. Pemerintah menargetkan untuk memindahkan 100.000 pengungsi ke Bhahsan Char secara berkala dari pengungsian yang penuh sesak dan menimbulkan berbagai macam permasalahan dari berbagai aspek seperti yang sudah dijelaskan sebelumnya (The Jakarta Post, 2020).

Kebijakan yang diambil oleh pemerintah Bangladesh ini merupakan bentuk respon darurat atau dalam pandangan Copenhagen disebut dengan emergency response terhadap situasi yang semakin sulit dan membahayakan keamanan nasional dan kehidupan normal warga negara asli Bangladesh, meskipun upaya ini belum mendapatkan persetujuan sepenuhnya dari United Nations tetapi kebijakan ini adalah langkah terbaik meskipun diluar kebijakan normal (outside normal policy) yang dapat dilakukan pemerintah Bangladesh terhadap pengungsi Rohingya. Para pengungsi yang sudah pindah dan mulai tinggal di pulau Bhahsan Char juga menyatakan bahwa kehidupan dan lingkungan di pulau tersebut jauh lebih baik ketimbang di wilayah pengungsian yang seperti tidak memiliki masa depan dan kejelasan (The Jakarta Post, 2020).

\section{KESIMPULAN}

Masalah-masalah yang timbul dan berkembang dengan keberadaan pengungsi Rohingya di Bangladesh dalam jangka waktu panjang mau tidak mau mendorong pemerintah Bangladesh sebagai securitisizing actor untuk mangupayakan langkah sekuritisasi sebagai bentuk perlindungan terhadap keamanan nasional dan warga negara Bangladesh (referent object). Permasalahanpermasalahan yang timbul seperti masalah kejahatan transnasional, masalah kesehatan dan lingkungan, dan masalah sosial-ekonomi berubah menjadi ancaman-ancaman yang sangat berpotensi mengancam kestabilan nasional dan kualitas hidup warga negara Bangladesh jika dibiarkan secara terus menerus. Keberatan yang disampaikan oleh pemerintah Bangladesh kepada United Nations merupakan bentuk speech act 
yang meminta perhatian global sebagai target audience agar tanggap (alert) dengan permasalahan yang dihadapi oleh pemerintah Bangladesh, bahwa permasalahan tersebut tidak dapat ditangani secara individu dan mebutuhkan respon global. Kebijakan yang diambil oleh pemerintah Bangladesh untuk membatasi akses para pengungsi dan memindahkan sebagian pengungsi secara berkala ke Bhahsan Char merupakan langkah terbaik dan bentuk respon darurat (emergency response) yang dapat dilakukan pemerintah Bangladesh untuk menjaga kestabilan nasional dan kualitas hidup warga negara Bangladesh.

Pemerintah Bangladesh dalam hal ini tidak memiliki maksud untuk menelantarkan para pengungsi Rohingya, kebijakan yang diambil berdasarkan pertimbangan pemerintah Bangladesh yang juga melihat kondisi Myanmar, yang merupakan negara asal dari para pengungsi yang sedang mengalami ketidakstabilan politik, sehingga kebijakan diluar normal (outside normal policies) harus diambil sebagai cara untuk menekan permasalahan yang sudah ada agar tidak semakin melebar dan membahayakan negara Bangladesh secara keseluruhan.

\section{REFERENSI}

Alam, S. (2018) Drug use among Bangladeshi children at alarming
levelAl. Anadolu Ajansı. Available at: https://www.aa.com.tr/en/asiapacific/drug-use-among-bangladeshichildren-at-alarming-level/1023044 (Accessed: June 20, 2021).

Banerjee, S. (2019) Drug Trafficking and Robingya Refugees in Bangladesh (Online). Available at: https://www.orfonline.org/expertspeak/drug-trafficking-and-rohingyarefugees-in-bangladesh-49005/ (Accessed: May 22, 2019).

Bashar, I. (2012) "Rohingyas in Bangladesh and Myanmar: Quest for a Sustainable Solution". RSIS Commentaries, Nanyang Technological University, Singapore., 1-4. doi:https://hdl.handle.net/10356/951 97

Bashar, I. (2017) "Exploitation of the Rohingya Crisis by Jihadist Groups: Implications for Bangladesh's Internal Security". Counter Terrorist Trends and Analyses, 9(9), 5-7. Retrieved from: http://www.jstor.org/stable/2635155 0 (Accessed: January 14, 2021).

Benar News. (2019) Minister: Bangladesh Spends \$300 Million Per Month on Robingya Refugees (Online). Available at: https://www.benarnews.org/english/ news/bengali/bangladesh-rohingya03082019153451.html (Accessed: February 8, 2021).

Chan, Emily Y.y., Cheuk Pong Chiu, and Gloria K.w. Chan. (2017) "Medical and Health Risks Associated with Communicable Diseases of Rohingya Refugees in Bangladesh". International Journal of Infectious Diseases68: 39-43. doi:10.1016/j.ijid.2018.01.001.

Chowdhury, J. (2019) Bangladesh, Growing Tired of Hosting Robingya Refugees, Puts New Squeeze on the Teeming Camps (Online). Available at: https://www.washingtonpost.com/w orld/asia_pacific/bangladeshgrowing-tired-of-hosting-rohingyarefugees-puts-new-squeeze-on-adisplaced- 
minority/2019/09/10/4488cfb4cfd5-11e9-a620-

0a91656d7db6_story.html (Accessed:

February 17, 2021).

Crabtree, Kristy. (2010) "Economic Challenges and Coping Mechanisms in Protracted Displacement: A Case Study of the Rohingya Refugees in Bangladesh". Journal of Muslim Mental Health5, no. 1: 41-58. doi:10.1080/15564901003610073.

Cresswell, J. (2014) Research Design. Sage Publications.

Dhaka Tribune. (2017) 'If we can feed 160m, We Can Also Feed 700,000 Robingya Refugees' (Online). Available at: https://www.dhakatribune.com/bang ladesh/2017/09/12/bangladesh-canfeed-700000-rohingya-refugees (Accessed: June 20, 2021).

Frieder, Max Levi. (2020) The Robingya Artolution: Teaching Locally Led Community-Based Public Art Educators in the Largest Refugee Camp in History. $\mathrm{PhD}$ diss., Teachers College, Columbia University.

Hadiwinata, Bob S. (2017) Studi Dan Teori Hubungan Internasional: Arus Utama, Alternatif, Dan Reflektivis. Jakarta: Yayasan Pustaka Obor Indonesia.

Hardoko, E. (2018) Bangladesh Tampung Lebih dari 1 Juta Pengungsi Robingya (Online). Available at: https://internasional.kompas.com/re ad/2018/01/17/15391021/banglades h-tampung-lebih-dari-1-jutapengungsi-rohingya (Accessed: January 5, 2021).

Hughes, C. W., \& Lai, Y. M. (2011) Security studies: A reader. London: Routledge.

Islam, M.M. \& Nuzhath, T. (2018) "Health Risks of Rohingya Refugee Population in Bangladesh: A call for Global Attention". Journal of Global Health, $8(2)$.
Milton, A., Rahman, M., Hussain, S., Jindal, C., Choudhury, S., Akter, S., ... Efird, J. (2017) "Trapped in Statelessness: Rohingya Refugees in Bangladesh". International Journal of Environmental Research and Public Health, 14(8), 942. doi:10.3390/ijerph14080942

Mukul, Sharif A., Saleemul Huq, John Herbohn, Ainun Nishat, A. Atiq Rahman, Raquibul Amin, and Farid Uddin Ahmed. (2019) "Rohingya Refugees and the Environment". Science364, no. 6436: 138. doi:10.1126/science.aaw9474.

New Age Bussiness. (2020) Bangladesh poverty rate rises to $35 \mathrm{pc}$ amid COVID-19 fallout: CPD (Online). Available at: https://www.newagebd.net/article/1 07855/bangladesh-poverty-rate-risesto-35pc-amid-covid-19-fallout-cpd (Accessed: June 20, 2021).

Parnini, Syeda Naushin. (2013) "The Crisis of the Rohingya as a Muslim Minority in Myanmar and Bilateral Relations with Bangladesh". Journal of Muslim Minority Affairs33, no. 2: 281-97. doi:10.1080/13602004.2013.826453.

Perdana, A. Vidya. (2019) Bangladesh Tak Mampu Lagi Terima Pengungsi Robingya Dari Myanmar (Online). Available at: https://internasional.kompas.com/re ad/2019/03/01/11291821/banglades h-tak-mampu-lagi-terima-pengungsirohingya-dari-myanmar (Accessed: August 8, 2020).

Qadri, Firdausi, Abul Kalam Azad, Meerjady Sabrina Flora, Ashraful Islam Khan, Md Taufiqul Islam, G. Balakrish Nair, Poonam Khetrapal Singh, and John D. Clemens. (2018) "Emergency Deployment of Oral Cholera Vaccine for the Rohingya in Bangladesh". The Lancet391, no. 10133: 1877-879. doi:10.1016/s0140-6736(18)30993-0.

Rahman, M.Z. \& Dodul, D.H. (2020) "Causing Security Threat to Host State by Refugees: Context of 
Rohingya Refugees in Bangladesh". Global Journal of Human-Social Science, pp.23-29.

Rahman, Utpala. (2010) “The Rohingya Refugee: A Security Dilemma for Bangladesh". Journal of Immigrant \& Refugee Studies8, no. 2: 233-39. doi:10.1080/15562941003792135.

Riley, Andrew, Andrea Varner, Peter Ventevogel, M. M. Taimur Hasan, and Courtney Welton-Mitchell. (2017) "Daily Stressors, Trauma Exposure, and Mental Health among Stateless Rohingya Refugees in Bangladesh". Transcultural Psychiatry54, no. 3: 304-31. doi:10.1177/1363461517705571.

Sajjad, Tazreena. (2021) As Bangladesh hosts over a million Rohingya refugees, a scholar explains what motivated the country to open up its borders (Online). Available at: https://theconversation.com/asbangladesh-hosts-over-a-millionrohingya-refugees-a-scholar-explainswhat-motivated-the-country-to-openup-its-borders-133609 (Accessed: February 8, 2021).

Summers, A., Humphpreys, A., \& Leidman, E. (2018) "Notes from the Field: Diarrhea and Acute Respiratory Infection, Oral Cholera Vaccination Coverage, and Care-Seeking Behaviors of Rohingya Refugees Cox's Bazar, Bangladesh". Morbidity and Mortality Weekly Report. doi:https://dx.doi.org/10.15585\%2F mmwr.mm6718a6.

Syed S Mahmood, Emily Wroe, Arlan Fuller, Jennifer Leaning. (2016) "The Rohingya people of Myanmar: health, human rights, and identity". Department of Medicine, Massachusetts General Hospital, Harvard Medical School, Boston, December 1. http://dx.doi.org/10.1016/ S01406736(16)00646-2.

The Jakarta Post. (2020) Bangladesh Moves More Robingya to Controversial Island
(Online). Available at: https://www.thejakartapost.com/new s/2020/12/28/bangladesh-movesmore-rohingya-to-controversialisland.html\#: :text=After $\% 20$ the $\% 20$ first $\% 20$ transfer $\% 20$ on,Bhashan $\% 20$ Char $\% 20$ is $\% 20 \mathrm{so}^{2} \% 20$ isolated (Accessed: February 8, 2021).

Ullah, Akm Ahsan. (2011) "Rohingya Refugees to Bangladesh: Historical Exclusions and Contemporary Marginalization". Journal of Immigrant \& Refugee Studies 9, no. 2 (2011): 13961. doi:10.1080/15562948.2011.567149.

UNHCR (n.d) Robingya Emergency (Online). Available at: https://www.unhcr.org/rohingyaemergency.html (Accessed:: June 20, 2021).

UNHCR. (2018) Culture, Context and Mental Health of Rohingya Refugees. Available at: https://www.unhcr.org/5bbc6f014.p df (Accessed:: June 20, 2021).

UNHCR. (2018) UN Launches 2018 appeal for Rohingya Refugees and Bangladeshi Host Communities (Online). Available at: https://www.unhcr.org/news/press/ 2018/3/5aabd2564/un-launches2018-appeal-rohingya-refugeesbangladeshi-host-communities.html (Accessed: June 20, 2021).

White, Kate. (2017). "Rohingya in Bangladesh: An Unfolding Public Health Emergency". The Lancet390, no. 10106: 1947. doi:10.1016/s01406736(17)32677-6.

WHO, 2019. WHO Bangladesh : Emergency_Rohingya Crisis. Available at: https://www.who.int/docs/defaultsource/searo/bangladesh/bangladesh ---rohingya-crisis---pdfreports/sitreps/2019/bi-weeklysituation-report-23---21-november- 
2019.pdf?sfvrsn=ba998d72_2

(Accessed: January 20, 2021).

WHO. (2017) 900,000 Vaccines "En Route" to Cox's Bazar To Prevent Cholera (Online). Available at:

https://www.who.int/southeastasia/n ews/detail/29-09-2017-900-000-

vaccines-en-route-to-cox-s-bazar-toprevent-cholera (Accessed: June 20, 2021).

WHO. (2018) One Million Robingya Refugees, Host Communities Being V accinated Against Cholera (Online). Available at: https://www.who.int/southeastasia/n ews/detail/03-05-2018-one-millionrohingya-refugees-host-communities- being-vaccinated-against-cholera (Accessed: February 8, 2021).

World Bank. (2017) Population, totalBangladesh (Online). Available at: https://data.worldbank.org/indicator /SP.POP.TOTL?locations=BD

(Accessed: June 20, 2021).

World Bank. (2021) Country Overview :

Bangladesh. World Bank. Available at: https://www.worldbank.org/en/coun try/bangladesh/overview (Accessed: June 20, 2021). 